\title{
Biodiversity and ecosystem functioning: issues of scale and trophic complexity
}

\author{
David Raffaelli* \\ Environment Department, University of York, Heslington, York YO10 5DD, UK
}

\begin{abstract}
Research on the relationship between biodiversity and ecosystem functioning is entering a new phase. The main driver behind this is an awareness that biodiversity loss operates at large spatial scales and generally involves reductions and changes in species at different trophic levels simultaneously. Evaluating how ecosystem processes are likely to change following species loss at multiple trophic levels will be difficult because of the feedbacks between levels and between levels and the ecosystem processes of interest. Similarly, carrying out manipulative experiments designed to accommodate multiple trophic levels at the landscape scales in which society is interested will be extremely challenging. Novel approaches, such as the BioMERGE (Biotic Mechanisms of Ecosystem Regulation in the Global Environment) initiative, are needed. In addition, future work should be more services-oriented, rather than process-oriented, if effects of biodiversity change on services are to be properly assessed. Finally, the application of mainstream ecosystem ecology to biodiversity-ecosystem functioning research seems to have been neglected to date. In this respect, there is potential for the mass-balance approach to contribute to the debate.
\end{abstract}

KEY WORDS: Food webs $\cdot$ Ecosystem services $\cdot$ Spatial scale $\cdot$ Species loss scenarios Resale or republication not permitted without written consent of the publisher

\section{INTRODUCTION}

The search for a relationship between biodiversity and ecosystem processes that underpin ecological services has led to an emerging paradigm (Naeem 2002), dominated by terrestrial ecologists to date. Whilst there were a few publications which explored this topic in the 1970s and 1980s, the bulk of published material comes from the 1990s, with an almost exponential increase to date, but relatively few papers that are marine oriented. Initially, this lack of engagement is surprising given the global importance of the marine environment $197 \%$ of the available living volume for biodiversity on the planet, $75 \%$ of the planet's surface area), the acknowledged importance of the oceans for the regulation of global geochemical cycles and the delivery by the oceans of goods and services to the world's population, the majority of which live along coastlines (Roberts \& Hawkins 1999). The reasons lie, in part, in the differences between the ways in which marine and terrestrial ecologists approach their science and in the cultural barriers between the 2 groups that have developed over the past 30 yr: the 2 groups read different journals, attend different meetings and speak different 'languages' (Raffaelli 2000a, 2005). It could be argued that there is as great a need for exchange between the different sub-disciplines of ecology as between the different disciplines of, say, ecology and economics.

Such barriers have certainly slowed the communication of novel approaches and perspectives concerning the relationships between biodiversity and ecosystem functioning from mainstream ecology to marine science. But the converse is also true: mainstream ecology has long neglected the exciting developments and opportunities provided by marine science. With respect to biodiversity and ecosystem functioning, one of the main issues under discussion has become which variable is dependent and which is independent. In other words, the degree to which biodiversity is shaped by, or shapes, ecosystem processes. There has been a shift in mainstream ecology in recent years such that the role of species composition in determining both qualitative and quantitative aspects of ecosystem processes is now clearly recognised (Naeem 2002). However, many 
marine ecologists are still adjusting to this perspective, and, thus, a widespread misperception remains that marine ecology has already addressed most aspects of biodiversity-ecosystem functioning (see for instance correspondence in Science, March 2005). This does not mean that earlier work in this area cannot be usefully re-focused to specifically address the presently emerging biodiversity-ecosystem paradigm (Naeem 2002). For instance, Emmerson \& Huxham (2002) have illustrated the potential of re-analysing data sets from earlier research programmes for generating novel insights at much larger spatial and temporal scales than is generally available from small-scale experimental studies. Indeed, marine ecologists are well accustomed to tackling issues of complexity and scale with which terrestrial ecologists are only now being confronted.

Here, I argue that the marine ecological community can build on the terrestrial-based studies that have been carried out to date (see also Bulling et al. 2006, in this Theme Section), draw on the rich history of established research in this general area and develop alternative approaches that may be more appropriate to the complexity and large-scale challenges of marine systems. First, I deal with issues of spatial and temporal scale, with respect to the utility of field experiments. This is followed by an exploration of the need to acknowledge the multi-trophic nature of real systemsthe differential losses of biodiversity at different trophic levels and how this varies with loss scenarios - and the complexity of the habitat networks operating within the essentially open nature of the marine system. I then discuss the difficult issues involved in linking biodiversity change to changes in the provision of goods and services in coastal systems, and, finally, I argue that an ecosystem-level approach is required for addressing what is essentially an ecosystem-level question.

\section{ISSUES OF SCALE}

A dominant feature of much research on biodiversity and ecosystem functioning is the use of manipulative field experiments (Bulling et al. 2006). Such experiments generate outcomes that are highly persuasive, because of the statistical rigour and power with which the data can be analysed. Research that involves experimental falsification of hypotheses is generally more persuasive than modelling studies, observations, logical argument and anecdote (Lawton 1996). Moreover, such research is much more likely to be published. However, there is always a trade-off to be made between spatial and temporal scales and the degree of replication of experimental and control plots (Raffaelli \& Moller 2000). This inevitably means that large-plot experiments tend to have relatively few replicates, and, in many cases, there are no replication or control plots at all (Raffaelli \& Moller 2000). Many of the earlier generation of biodiversity-ecosystem function experiments had a high degree of replication, but small plot sizes (Bulling et al. 2006); in the new generation of terrestrial studies, experiments are not as constrained (e.g. Schilthuizen 2003, Scherer-Lorenzen et al. 2004).

What then is the appropriate plot size for biodiversity-ecosystem functioning experiments? Not surprisingly, many experimentalists take a purely pragmatic approach to this question. Thus, in an interview survey of ecologists who have carried out predator-prey manipulation experiments at the largest plot sizes (hectares or square kilometres), the stated reasons for choosing a particular size included the following: this was the maximum plot size that could be handled by the researcher, that was all the space available for the work, and this was the minimum area required to ensure that the response variable was informative (Raffaelli \& Moller 2000). Of all the responses, only the last was not purely pragmatic, but based instead on the attributes of the system and experiment, in other words, the aspects that should drive experiments in biodiversity-ecosystem functioning. It is important to define a priori the response variable of interest and its characteristic scale of heterogeneity. However, it is tempting to measure many different kinds of response variables from the same plots for the sake of economy, but this could result in a mismatch of scale if the manipulation (e.g. number of species) is maintained at square metre scales and response variables are measured at much smaller scales. For instance, many response variables measured in marine (and terrestrial) experiments can now be measured at micro-scales, such as oxygen concentration or redox potential in intact cores of benthic material (see papers in Solan et al. 2003). Whilst technically impressive, there is clearly a mismatch between the scale at which the response or dependent variable is measured (microns to millimetres) and the scale at which the independent variable (macrofaunal biodiversity) operates (100s to $1000 \mathrm{~s} \mathrm{~cm}^{2}$ or even many square metres). A central question is whether the bulk (entire plot) estimate of oxygen concentration is likely to be different from that estimated by replicate micro-measurements. Until the effects of measurement of such variables at different scales can be properly compared, it will be difficult to design and interpret experiments with complete confidence. In addition, there is often some confusion about plot size and scale in the design of manipulative experiments (Raffaelli \& Moller 2000). Large plot sizes will only be large scale relative to the life space of the species (or system) of interest. For instance, a $1 \mathrm{~m}^{2}$ plot that represents the home range of a rocky shore limpet may be 
equivalent to a $10000 \mathrm{~km}^{2}$ plot for a polar bear. Few experiments really explore the effects of increasing scale per se, and those that do (e.g. Thrush et al. 1996, 1997) indicate that outcomes are often scale dependent.

Reasons for deciding on a particular duration of a field experiment have, like plot size, been mostly based on pragmatic considerations (Raffaelli \& Moller 2000), including the need to accommodate the work within the time available in a research studentship or grant and the difficulties of maintaining the experimental set-up in a hostile physical environment. This latter point is extremely relevant to work in marine systems where ecologists are often faced with severe practical difficulties in carrying out their experiments. A few respondents to the survey of Raffaelli \& Moller (2000) estimated the required duration of the experiment based on the dynamics of the response variables (prey species generation times). There are few 'rules' available for making such decisions a priori. A ruleof-thumb similar to that proposed for food-web experiments by the late Peter Yodzis (Yodzis 1988) needs, urgently, to be developed for work on biodiversity-ecosystem functioning. Based on experience from other kinds of experiments, it is likely that the outcome of any experiment will be scale dependent and that short-term responses will be qualitatively and quantitatively different from longer-term responses (Raffaelli \& Moller 2000).

Carrying out experiments on biodiversity-ecosystem functioning at the spatial and temporal scales appropriate to those questions in which society is interested will inevitably involve large plot sizes and reduced replication, perhaps no replication at all, as well as long time scales. But should lack of replication deter an experimental approach? Assuming grant-awarding agencies are satisfied by the arguments, it should be possible to present a case as persuasive as that presented by highly replicated experiments. The persuasive power of large-scale experiments will lie not in the number of degrees of freedom available, but in whether the magnitude of the response to the manipulation (the effect size) is large. In contrast, quite small effect sizes (a few percent difference between controls and treatment) will be statistically significant if sufficient replicates are used, but such effects may be trivial as far as society is concerned. This point is well made by experiments in marine intertidal systems on the role of starfish as keystone predators (Paine 1974) and of the limpet Patella as a grazer on rocky shores (Lodge 1948, Jones 1948, reviewed in Hawkins \& Hartnol 1983). These experiments were large scale, poorly or un-replicated, and 2 of them lacked control plots altogether. The persuasive power of these experiments lay in the magnitude of the observed effect (extremely large and impressive), and, just as importantly per- haps, its direction; the response observed was entirely at odds with the accepted view of how those systems were normally structured (for a more detailed treatment see Raffaelli \& Moller 2000)). The downside of performing large-scale, unreplicated experiments is that if the effect size is small, say on the order of $10 \%$, then the scientific world will remain unconvinced. The approach is not for the faint hearted.

\section{ISSUES OF COMPLEXITY}

The majority of manipulative experiments designed to address the relation between biodiversity and ecosystem functioning have focused largely on a single trophic level or taxonomic grouping within a much larger food web (Raffaelli et al. 2002, Bulling et al. 2006), for example, the early experiments by Tilman (1997) at Cedar Creek on grassland plants, the Biodepth experiments made across Europe (Hector et al. 1999) and the experiments carried out on marine benthic systems by our own group (Emmerson et al. 2001, Raffaelli et al. 2003). In studies where the effects of, and on, trophic levels other than those directly manipulated have been investigated, these investigations have tended to be supplementary experiments rather than something which was explicitly accommodated for within the main design (Raffaelli et al. 2002).

Whilst the work with single trophic levels has advanced the biodiversity-ecosystem functioning debate significantly, particularly for improving the understanding of mechanisms and the development of models, the single trophic level approach has a number of limitations. One of the motivations for exploring the relation between biodiversity and ecosystem function has been to predict the consequences of species loss from ecological systems. However, the majority of single trophic level approaches have not addressed the effects of species loss per se (communities are artificially assembled, not dissembled), or the ways in which biodiversity loss at several trophic levels affects functioning either through simultaneous loss of species or through subsequent cascading effects. In addition, different causes of biodiversity loss are expected to affect different trophic levels in very different ways. This is not by any means a rejection of single-level experiments; such designs will remain important for exploring biodiversity effects and identifying mechanisms. However, they need to be complemented by other approaches, with a focus on larger scales and the effects of biodiversity loss per se.

Carrying out whole food web experiments at large scales is probably neither feasible nor ethical, and alternative approaches need to be identified for which marine ecologists are well equipped. Re-analysis of 
earlier large-scale studies involving many species, but which were not framed within the biodiversityecosystem functioning paradigm (e.g. Emmerson \& Huxham 2002), is potentially a cost-effective way to explore, confirm, or refute novel hypotheses and to formulate new ones, which could then be tested experimentally, perhaps in small-scale systems. However, data-mining approaches are not without their problems, and one needs to proceed with caution. For instance, in much of the historical literature, the assumption has been that biodiversity is the dependent variable which responds to changes in ecosystem processes (the independent variable). Although a case can be made for the converse using the same data (Emmerson \& Huxham 2002), those data were never collected with this particular form of the relationship in mind. It will always be difficult to tease out the cause-effect relationships in such data, and the possibility of confounding effects is high. Nevertheless, it makes sense to use this wealth of literature on marine (and terrestrial) systems to, at least, establish whether the data are consistent with current theory, before embarking on novel and expensive experimental research programmes.

A different approach to the use of existing biodiversity and ecosystem process data is provided by the recent BioMERGE (Biotic Mechanisms of Ecosystem Regulation in the Global Environment) initiative on the functioning of benthic communities under a variety of realistic loss scenarios (Solan et al. 2004, Naeem 2006, in this Theme Section). Here, a specific ecosystem process, the depth of biological perturbation (biological mixing depth, BMD) of the upper sediment layers, a proxy for the fluxes of major nutrients, can be estimated from empirical knowledge of a few of the biological traits (e.g. size, mobility) of the species present. Different species-loss scenarios (over-fishing, enrichment, habitat destruction) were applied by Solan et al. to assemblages so that species were lost from those assemblages according to their sensitivities to each scenario (see also below). Using this approach, Solan et al. (2004) were able to show that the effects of biodiversity loss on the functioning of ecosystems will depend largely on the order in which species are lost, in turn, determined by their susceptibilities to different types of impact. Such approaches have a high potential for successfully exploring the consequences of biodiversity loss at large spatial and long temporal scales using the extensive datasets already available for many marine areas.

The assemblages analysed by Solan et al. (2004) also comprised many different trophic types, an advance in com- parison to single trophic level experiments. Even so, these assemblages do not reflect the larger food web including fish and other consumers, although there is no reason why the approach could not be extended to include higher trophic levels if such data were available. One of the challenges in this respect will be to develop ways of accommodating the different spatial and temporal scales over which different trophic levels operate. Larger-bodied taxa at higher trophic levels usually have greater longevity, longer generation times and range over a larger area than those at lower trophic levels, which are typically recorded at scales smaller than square metres.

Taking a multi-trophic approach to biodiversityecosystem functioning research really does matter. There are likely to be significant feedbacks between the trophic level manipulated and the higher and lower trophic levels, as well as with the response process of interest (Fig. 1). If these feedbacks are not recognised and accounted for, the outcomes of single trophic level experiments will be of limited value for policy makers interested in the impacts of biodiversity loss (Raffaelli et al. 2002). For instance, our own benthic biodiversity experiments demonstrate that the greater the biodiversity of macroinvertebrates within the sediment, the more ammonium is released from the sediment due their bioturbation activities (Emmerson et al. 2001, Raffaelli et al. 2003). It is also known that benthic macroalgae (Enteromorpha intestinalis, Chaetomorpha linzii and Ulva lactuca) in this particular system can use ammonium as a source of nitrogen (Taylor \& Raven 2003), so that algal growth will be stimulated by a higher macrofaunal species richness within the sediment; this has now been demonstrated experimentally in a series of mesocosm experiments (M. Solan et al. unpubl. data). Enhanced growth of benthic macroalgae, in turn, depresses macrofaunal biodiversity and changes the redox chemistry within

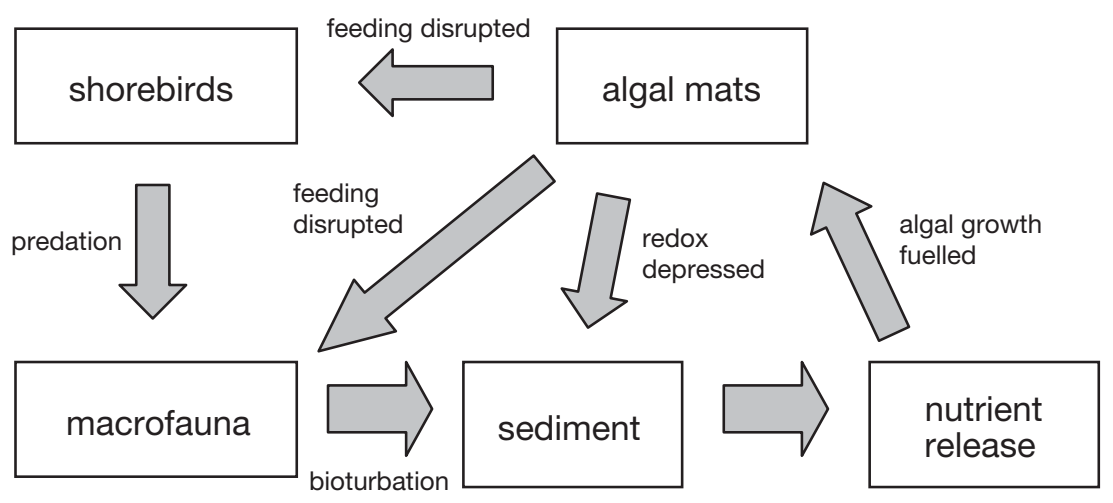

Fig. 1. Interactions and feedbacks between macrofaunal species richness (manipulated variable), nutrient release (ecosystem function response variable) and other trophic levels. Based on known relationships within the Ythan estuary food web, Aberdeenshire, Scotland 
the sediment (Raffaelli 2000b), as well as presenting a barrier to the selective feeding of higher trophic levels, especially fish and shorebirds (Raffaelli et al. 1998), and these species may then leave the location altogether (Raffaelli et al. 1999) (Fig. 1). The feedbacks on macrofaunal diversity will, in turn, alter ammonium release, so that the net effects of macrofaunal species richness on ecosystem functioning will be much more complex than is revealed in single trophic level experiments.

A further reason for adopting a multi-trophic perspective is the need to recognise that impacts which lead to biodiversity loss usually occur across all trophic levels and that, as Solan et al. (2004) have shown, taxa will differ in their sensitivities to particular loss scenarios (Fig. 2). Thus, top predators in marine systems tend to have a large body size, low abundance and greater longevity than species lower in the food web. Largebodied taxa are particularly vulnerable to habitat fragmentation/destruction, but may be less susceptible to contaminant stress, which hits smaller species disproportionately hard. In contrast, there are usually more species at lower trophic levels, resulting in greater functional redundancy and more insurance against the effects of biodiversity loss. These species also have higher generation rates and, thus, a greater capacity for adaptive change. Biodiversity loss is, therefore, likely to be distinctly non-random and dependent on
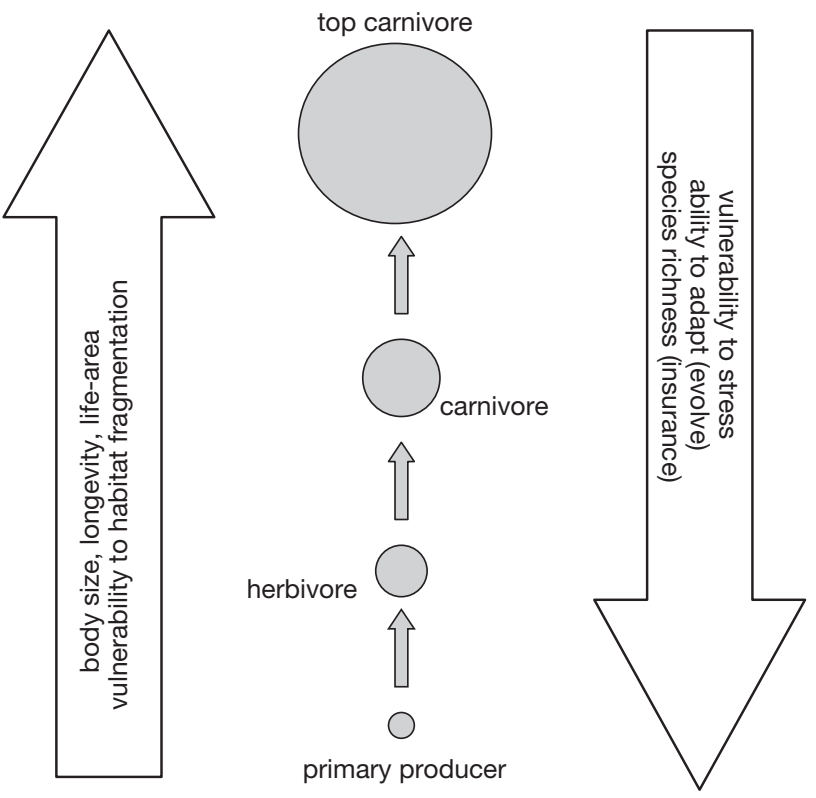

Fig. 2. Variation in traits, species richness and vulnerability to extinction in a model food web

the loss scenario. There is empirical evidence for the distribution of the traits shown in Fig. 2 (Petchey et al. 2004) in freshwater food webs, and an example is provided in Fig. 3 for an estuarine food web.

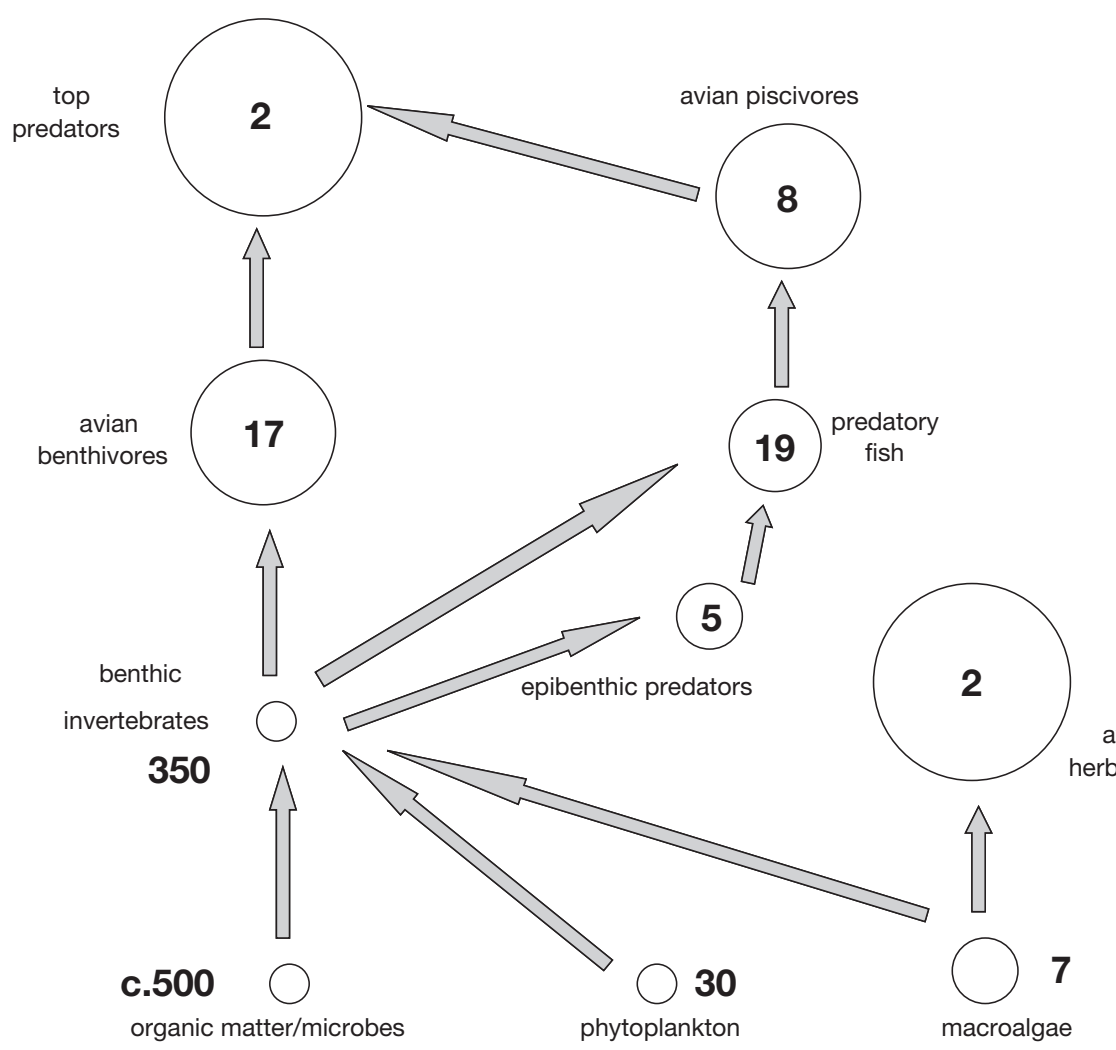

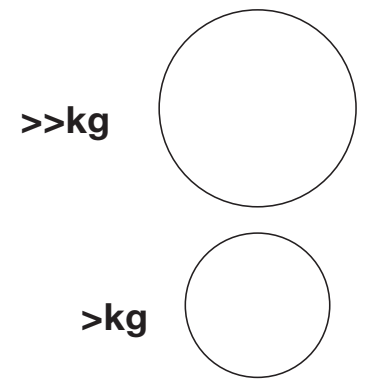

kg<smiles>C1=CCCCCCCCCCC1</smiles>

mg

Fig. 3. Variation in body size (circles) and species richness (numbers) with trophic position in the Ythan estuary food web. From Hall \& Raffaelli (1991) and Leaper \& Raffaelli (1999) 
Future research aiming to mimic realistic extinction scenarios needs to recognise that ecological systems are often subjected simultaneously or sequentially to a board range of stressors. For example, key estuarine stressors include habitat loss and alteration, eutrophication, sewage, fisheries overexploitation, altered freshwater flows, invasive species and sea level rise (Kennish 2002). For many estuaries, these stressors act simultaneously, and their combined effects are not easy to predict: stressors can act synergistically, antagonistically, or additively, depending on the system and stressor. Thus, low oxygen and high contaminant loads may be insufficient to cause biodiversity change on their own, but, in combination, the effects may be overwhelming. Also, different stressors may act on different life-stages of commercially or ecologically important marine species, depending on their body size and, hence, sensitivities. A combination of commercial exploitation of fish and shellfish targeted at adults and habitat destruction of spawning grounds might be expected to have a greater impact than either stressor alone. In other words, impacts regarded as less acute, or even benign, may become significant when they operate in combination. Incorporating such considerations into approaches to biodiversity-ecosystem function research will be a major but necessary challenge.

A neglected area of ecological complexity that is highly pertinent to biodiversity-ecosystem functioning research is the level at which biodiversity is considered. Much of the recent work in this field focuses on species as the basic datum, with an increasing recognition that functional groupings of species may be more relevant than species per se. However, the term 'biodiversity' can mean all things to all people, and the working concept used by many policy makers is just as likely to be an even higher level property such as landscape units or communities, as defined by the Convention on Biological Diversity (CBD 2004). In a thoughtful essay, Hawkins (2004) points out that, unlike the terrestrial environment, marine coastal systems are much more open, with connections between major habitat patches driven by water movement at a variety of scales: upwelling, currents and waves. For example, kelp forests are amongst the most productive habitat units on Earth, but most of the production can be exported to other habitat units, such as sandy beaches (Raffaelli \& Hawkins 1996). He argues that in the case of such complex, open systems the highly reductionist experimental approach that focuses on species within a habitat type is inappropriate. A more holistic approach is required, combining in situ estimates of ecosystem processes with modelling of the connectivity between habitat units (see also Giller et al. 2004).

\section{LINKING BIODIVERSITY TO ECOSYSTEM SERVICES}

Whilst the measurement of ecosystem processes under different levels of biodiversity is relatively straightforward, extending the linkages to ecosystem goods and services has been more difficult for a number of reasons. First, many of the services which ecosystems provide to society are underpinned by several, often many, ecosystem processes making direct mapping of biodiversity loss onto changes in the provision of services difficult (Fig. 4). A second issue is that the further the process or service from the biodiversity itself, the weaker the relationship will be, generating uncertainties in management and policy decisions. For instance, there is an intimate linkage between plant species richness and primary production, so that the effects of biodiversity change on this process are direct and strong. In other words, there is likely to be a large effect size in such experiments. In contrast, there will be several steps (sediment disturbance, changes in the sediment microbial assemblages and their activities) involved between changes in benthic invertebrate species richness and primary production by phytoplankton in the overlying water column, and the effects observed are expected to be weaker. Additional linkages to ecosystem services may also reduce the magnitude of a biodiversity effect, since many different processes will be involved, some direct, some indirect (Fig. 4). As Hawkins (2004) has argued (see above), this is likely to be particularly true for open marine systems. Thirdly, different biodiversity loss scenarios will affect processes and services in quite different ways depending on the identity or function of the species most affected (Fig. 2), so that it may be difficult to establish general rules linking biodiversity changes to ecosystem service delivery.

Given these issues, especially the multi-process underpinning of services, perhaps ecologists should not be attempting to link effects from biodiversity to

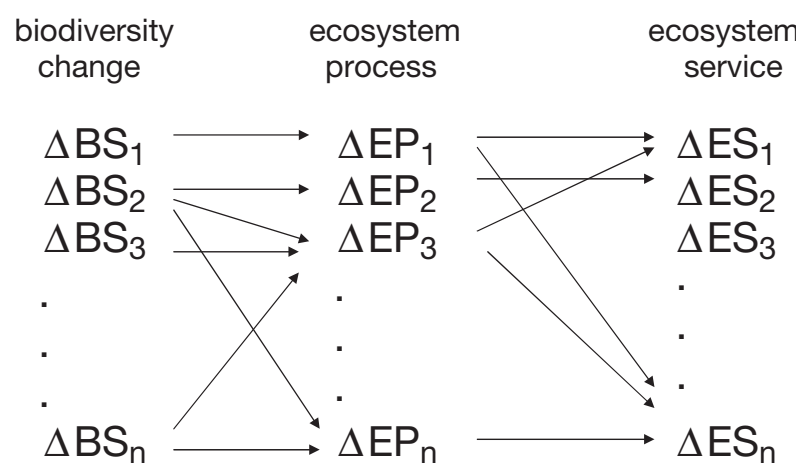

Fig. 4. Possible links between changes in biodiversity $(\Delta \mathrm{BS})$, ecosystem processes $(\Delta \mathrm{EP})$ and services $(\Delta \mathrm{ES})$ 
processes and then on to services, but start from the service itself. First, identify the service of interest (e.g. coastal protection, detoxification, or spiritual enhancement), then identify the key processes affecting delivery of that service, and then design research programmes that explore the effects of changes in the relevant biodiversity on those processes (Table 1). The service-orientated approach has the advantage that the importance of changes in relevant biodiversity can be assessed much less ambiguously, and, hence, more persuasively to policy makers, than is presently the case. Kremer (2005) provides some thoughtful insights into some general issues related to establishing linkages between biodiversity and services.

\section{PUTTING THE ECOSYSTEM INTO BIODIVERSITY-ECOSYSTEM FUNCTIONING RESEARCH}

I have argued that the marine research community is well equipped to move beyond small-scale approaches and adopt landscape-scale initiatives with a multitrophic perspective and, almost certainly, using a nonexperimental, macro-ecological approach of the kind exemplified by Solan et al. (2004). Naeem (2006) makes a similar plea. Working at the ecosystem scale on ecosystem processes requires an ecosystem science approach. Ecosystem science has a long history in both the aquatic and terrestrial sciences, but is not well articulated within the present biodiversity-ecosystem functioning research community. In part, this must be because many of the personalities involved in biodiversity-ecosystem functioning research come from the academic stable of population and community ecology, rather than ecosystem ecology. The division between population and ecosystem ecologists seems to be a cultural phenomenon, consistent with Holling's (1992) comment that 'community ecology and ecosystem ecology seem to have existed in different worlds'. Population and community ecology has traditionally focussed

Table 1. A service-orientated approach for identifying the relevant underpinning processes and biodiversity elements in marine coastal systems. Note that some ecological goods, such as marine pharmaceuticals and culture, aesthetics and recreation, have no obvious 'process' underpinning them

\begin{tabular}{|lll|}
\hline Service & Ecosystem process & Relevant biodiversity \\
\hline Fibre/timber/fuel & Primary production & Mangrove trees \\
Fertility/nutrient cycling & Nutrients from sediment & Benthic infauna \\
Waste processing & Nutrient stripping & Salt marsh plants \\
Flood protection & Primary production & Marine vegetation \\
Pharmaceutical & & Corals, sponges \\
Cultural/amenity & & Shorebirds \\
Food & Secondary production & Estuarine bivalves \\
\hline
\end{tabular}

on basic studies, interactions amongst biota and the formulation of general and simple theories, whilst ecosystem ecology has concerned itself with specific applied problems, biotic, abiotic and human interactions, producing a catalogue of specific examples from which generalisation is difficult (Holling 1992). As with terrestrial and marine ecologists, there has been a divergence between the population ecology and systems ecology communities; these communities now seem to have different languages, attend different conferences and publish in different journals (Raffaelli 2000a, 2005). However, the divide has recently become less pronounced, with population and community ecologists increasingly tackling applied issues in sustainable resource management, whilst ecosystem ecologists are starting to generate general theories from the wide range of applied studies now available (Holling 1992), especially in the areas of network analysis and thermodynamics (e.g. Ulanowicz 1986, Christensen \& Pauly 1992, Jørgensen 1997). In addition, there is a growing awareness by all ecologists that ecosystems are, in part, shaped by the activities of their biodiversity.

In addition to the logic of taking an ecosystem approach to an ecosystem-level question, there is a second benefit of unifying efforts with respect to policies on biodiversity protection, in particular through the Convention on Biological Diversity. The signatories of this convention are requested to apply the ecosystem approach to biodiversity conservation and management, based on a set of principles (the Malawi principles) agreed upon in 1998 and formally adopted by the Conference of the Parties in 2000. The ecosystem approach was adopted by the World Summit on Sustainable Development in Johannesburg 2002, and has been recommended for adoption for many major policy initiatives in Europe, including the EU Water Framework Directive, Common Fisheries Policy and the European Marine Strategy (CBD 2004). An important feature of the ecosystem approach is that it is truly interdisciplinary and involves many socio-economic components. For instance, the objectives of management are regarded as a matter of societal choice, and the system should be understood and managed in an economic context. In addition, the approach should be taken at the appropriate (large) spatial and temporal scales, recognising temporal lags between different scales, and the conservation of ecosystem functioning should be a priority, in order to maintain ecosystem services (CBD 2004). There are clearly many points of contact between this policy and biodiversity-ecosystem research, as well as mainstream ecosys- 
tem ecology, which enlists a large-scale approach that has increasingly considered socio-economic dimensions (Gunderson \& Holling 2002).

Developments in ecosystem ecology have been based largely on the way energy (or rather its useful form, exergy; Jørgensen 1997) is distributed amongst system components and on how this distribution changes from early to mature stages of ecosystem development. Much of ecosystem ecology can thus be understood within a thermodynamics framework (Odum 1969, 1985), where systems are seen to move further away from thermodynamic equilibrium as they develop or mature. Whilst the approach has always had its critics (e.g. Mansson \& McGlade 1993), recent work by Joao Marques, Sven Jørgensen and their colleagues (Jørgensen \& Marques 2001, Marques \& Jørgensen 2002) has illustrated how population and community ecology-based approaches can be accommodated within a thermodynamics framework, thereby potentially bringing ecosystem ecology to bear on biodiversity-ecosystem functioning issues. Of particular relevance is their interpretation of the study by Wilsey \& Potvin (2000) on the effects of changes in the evenness component of plant species diversity on primary productivity (Marques \& Jørgensen 2002). They equate increasing evenness with information manipulation that artificially moved the system further from dynamic equilibrium to create a more efficient dissipative structure that increased exergy storage as biomass. By translating the biodiversity effects observed by Wilsey \& Potvin (2000) into the language of ecosystem ecology, Marques \& Jørgensen (2002) illustrated the potential of ecosystem ecology in the arena of biodiversity-ecosystem functioning research.

Mass-balance models and network analysis (Ulanowicz 1986, Christensen \& Pauly 1992) provide reasonably accessible frameworks within which the effects of biodiversity change within a food web can be explored in relation to ecosystem-level attributes related to ecological functioning. Here, I provide an example, purely for illustrative purposes, based on a mass-balance model developed for the food web of Ythan estuary, Aberdeenshire. The functions of interest are measures of the information content, the cycling of energy and the distribution of flows within the ecosystem; all are related to how far the system moves from its 'stable' configuration and the amount of whole-system productivity. By deleting species from the system (biodiversity loss) and re-balancing the model, the effects of these functions on a food web scale can be appreciated. Of course, the species deletion approach has been commonly used in stability analysis of food web models (e.g. Pimm 1981), but here a range of whole-system attributes rather than a single function, dynamic stability, can be evaluated.
The version of the Ythan food web used here comprises 28 taxa: shorebirds-cormorant, shelduck, eider, red breasted merganser, oystercatcher, dunlin, redshank, wigeon, mute swan; dominant fish-flounder, goby, 'other fish'; epibenthic crustaceans-shore crab, brown shrimp; benthic invertebrates-Mytilus edulis, Nereis diversicolor, Corophium volutator, Gammarus spp., Littorina spp., Hydrobia ulvae, Macoma balthica and meiofauna; zooplankton; benthic green algae; other macrophytes; benthic microphytes; and detritus. These taxa are distributed across 4 trophic levels. For computational reasons, this version of the Ythan web is somewhat smaller than the version with ca.100 taxa described elsewhere (Hall \& Raffaelli 1991, Huxham et al. 1995), but the web contains all of the major elements with which the species to be manipulated are connected. The model was constructed within the package Ecopath 5.0 (Christensen et al. 2002).

Three benthic species within the food web have provided the main focus for previous work on biodiversity-ecosystem functioning relationships in the sediments of the Ythan (Emmerson et al. 2001, Raffaelli et al. 2003), specifically the polychaete Nereis diversicolor, the amphipod Corophium volutator and the snail Hydrobia ulvae. Several sets of mesocosm experiments in which each of these species were maintained individually and in different combinations indicate that the 3 species differ markedly in their relative contributions to ecosystem functioning (ammonium release from the sediment), with $N$. diversicolor having the greatest effects, and $H$. ulvae, the least. The effects of species loss will, thus, depend greatly on the order in which species are lost (Emmerson et al. 2001, Solan et al. 2004). Whilst the mesocosm experiments focussed on a single process (i.e. nutrient release), the mass-balance model approach allows effects of species loss on a variety of whole-system attributes (i.e. ecosystem functions) to be explored.

Each of the 3 invertebrate species was removed from the food web model, and the model was then re-balanced to calculate the new values for ecosystem functions (Table 2). Loss of any of the 3 species reduced ascendancy, overhead (hence, capacity), throughput and total respiration and increased throughput cycling, indicating that the system had moved nearer to thermodynamic equilibrium. Not surprisingly, the loss of only 1 of 28 species from the system had little effect on the system's overall information content (Table 2). Of the 3 species, Nereis diversicolor changed key system attributes more than either Corophium volutator or Hydrobia ulvae, but there is no consistent association between species biomass and effects for the latter 2 species (Table 1). N. diversicolor has by far the largest standing stock biomass, but $C$. volutator and $H$. ulvae have higher production to biomass $(P / B)$ ratios, so that their roles in shunting energy through the food web 
Table 2. Nereis diversicolor, Corophium volutator, Hydrobia ulvae. Effects on ecosystem-level functions of removing key species of macrofauna from a mass-balance model of the Ythan estuary food web. Percent of total values in parentheses. P/B ratio: production to biomass ratio; ascendancy: the average information in a system, scaled by system throughput, and believed to increase with system development; overhead: how much 'strength in reserve' the system has to cope with future perturbations; capacity: the upper limit for ascendancy; information: the information content in the system; throughput: the sum of all the flows in the system; respiration: the sum of the respiration across all taxa; Finn's index: the fraction of a system's throughput which is recycled

\begin{tabular}{|c|c|c|c|c|c|}
\hline Ecosystem attribute & sturbed food web & Nereis removed & Corophium removed & Hydrobia removed & Species effects \\
\hline Biomass $\left(\mathrm{t} \mathrm{km}^{-2}\right)$ & - & 185 & 82 & 17 & \\
\hline$P / B$ ratio & - & 1 & 3 & 3 & \\
\hline Ascendancy & $\begin{array}{l}29228 \\
(24.9)\end{array}$ & $\begin{array}{c}24949 \\
(25.9)\end{array}$ & $\begin{array}{l}27957 \\
(25.6)\end{array}$ & $\begin{array}{c}27304 \\
(25.8)\end{array}$ & $\mathrm{N}>\mathrm{C}>\mathrm{H}$ \\
\hline Overhead & $\begin{array}{l}88342 \\
(75.1)\end{array}$ & $\begin{array}{c}71489 \\
(74)\end{array}$ & $\begin{array}{l}81111 \\
(74.4)\end{array}$ & $\begin{array}{l}78677 \\
(74.2)\end{array}$ & $\mathrm{N}>\mathrm{H}>\mathrm{C}$ \\
\hline Capacity & 117586 & 96438 & 109101 & 105997 & \\
\hline Information & 1.17 & 1.16 & 1.17 & 1.16 & $\mathrm{~N}, \mathrm{H}>\mathrm{C}$ \\
\hline Throughput & 24900 & 21502 & 23916 & 23569 & $\mathrm{~N}>\mathrm{H}>\mathrm{C}$ \\
\hline Respiration & 4410 & 3565 & 4243 & 4011 & $\mathrm{~N}>\mathrm{H}>\mathrm{C}$ \\
\hline Finn's index (\% total throughput) & 35.4 & 32.4 & 34.9 & 34.9 & $\mathrm{~N}>\mathrm{H}, \mathrm{C}$ \\
\hline Throughput cycled $\left(\mathrm{t} \mathrm{km}^{-2} \mathrm{yr}^{-1}\right)$ & 4.31 & 5.26 & 5.26 & 4.51 & $\mathrm{~N}, \mathrm{C}>\mathrm{H}$ \\
\hline
\end{tabular}

are much greater than their standing stock biomass indicates. It would appear that, at least compared to $C$. volutator and $H$. ulvae, the loss of $N$. diversicolor from the Ythan food web would have system-level impacts in addition to those already documented for nutrient cycling (Emmerson et al. 2001, Raffaelli et al. 2003).

\section{CONCLUSIONS}

It is clear that marine ecologists are well equipped to explore the relationships between biodiversity and ecosystem functioning, building on the strong foundations laid by previous marine research programmes. As is the case for terrestrial systems, there is a need to move towards larger spatial and temporal scales, towards greater trophic complexity and towards connections to biodiversity policy being developed at the ecosystem level. Small-scale experiments will remain useful for identifying mechanisms and testing specific hypotheses, but macro-ecological and ecosystem ecology approaches have potential for successfully addressing issues of scale, complexity and socio-economic concerns. In particular, marine ecologists need to recognise that their system is much more open than most of the terrestrial systems in which much of the biodiversity-ecosystem functioning research has been carried out to date, and they have, by necessity, an opportunity to explore how local-scale relationships and processes might be manifested at larger regional scales.

Acknowledgements. It is a great pleasure to acknowledge the constructive suggestions and advice of Steve Hawkins and Beccy Leaper on an earlier version of this paper. Steve reminded me of the important ideas and exchanges on the open nature and connectivity of landscape units that came out of the ESF Ascona workshops, April 2002, whilst Beccy enabled me to see that marine ecologists have much to be proud of in this area and need not slavishly repeat the approaches taken by terrestrial ecologists. Thanks.

\section{LITERATURE CITED}

Bulling MT, White PCL, Raffaelli D, Pierce GJ (2006) Using model systems to address the biodiversity-ecosystem functioning process. Mar Ecol Prog Ser 311:295-309 (in this Theme Section)

CBD (Convention on Biological Diversity) (2004) Available at www.biodiv.org/programmes/cross-cutting/ecosystem/

Christensen V, Pauly D (1992) ECOPATH-a software for balancing steady-state ecosystem models and calculating network characteristics. Ecol Model 61:169-185

Christensen V, Walters CJ, Pauly D (2002) Ecopath with ecosim, Ver 5. Available at www.ecopath.org

Emmerson MC, Huxham M (2002) How can marine ecologists contribute to the biodiversity ecosystem functioning debate? In: Loreau M, Inchausti P, Naeem S (eds) Biodiversity and ecosystem functioning: synthesis and perspectives, Oxford University Press, Oxford, p 139-146

Emmerson MC, Solan M, Emes C, Paterson DM, Raffaelli DG (2001) Consistent patterns and the idiosyncratic effects of biodiversity in marine ecosysytems. Nature 411:73-77

Giller PS, Hillebrand H, Berninke UG, Gessner MO and 8 others (2004) Biodiversity effects on ecosystem functioning: emerging issues and their experimental test in aquatic environments. Oikos 104:423-436

Gunderson LH, Holling CS (2002) Panarchy: understanding transformations in human and natural systems. Island Press, Washington, DC

Hall SJ, Raffaelli DG (1991) Food web patterns: lessons from a species rich web. J Anim Ecol 60:823-841

Hawkins SJ (2004) Scaling up: the role of species and habitat patches in functioning of coastal ecosystems. Aquat Conserv Mar Freshw Ecosyst 14:217-219

Hawkins SJ, Hartnol R (1983) Grazing of intertidal algae by marine invertebrates. Annu Rev Mar Biol Oceanogr 21: 195-282

Hector A, Schmid B, Beierkuhnlein C, Caldeira MC and 30 
others (1999) Plant diversity and productivity experiments in European grasslands. Science 286:1123-1127

Holling CS (1992) Cross-scale morphology, geometry and dynamics of ecosystems. Ecol Monogr 62:447-502

Huxham M, Raffaelli DG, Pike AW (1995) Parasites and food web patterns. J Anim Ecol 64:168-176

Jones NS (1948) Observations and experiments on the biology of Patella vulgata at Port St. Mary, Isle of Man. Proc Trans Liverpool Biol Soc 56:60-77

Jørgensen SE (1997) Integration of ecosystem theories: a pattern, 2nd edn. Kluwer, Dordrecht

Jørgensen SE, Marques JC (2001) Thermodynamics and ecosystem theory, case studies from hydrobiology. Hydrobiologia 445:1-10

Kennish M (2002) Environmental future of estuaries. Environ Conserv 29:78-107

Kremer C (2005) Managing ecosystem services: What do we need to know about their ecology? Ecol Lett 8:468-479

Lawton J (1996) Patterns in ecology. Oikos 75:145-147

Leaper R, Raffaelli DG (1999) Defining the body sizeabundance constraint space: data from a real web. Ecol Lett 2:191-199

Lodge SM (1948) Algal growth in the absence of Patella on an experimental strip of foreshore, Port St. Mary, Isle of Man. Proc Trans Liverpool Biol Soc 56:78-83

Mansson BA, McGlade JM (1993) Ecology, thermodynamics and H. T. Odum's conjectures. Oecologia 93:582-596

Marques JC, Jørgensen SE (2002) Three selected ecological observations interpreted in terms of a thermodynamic hypothesis. Contribution to a general theoretical framework. Ecol Model 158:1-9

Naeem S (2002) Ecosystem consequences of biodiversity loss: the evolution of a new paradigm. Ecology 83:1537-1552

Naeem S (2006) Expanding scales in biodiversity-based research: challenges and solutions for marine systems. Mar Ecol Prog Ser 311:273-283 (in this Theme Section)

Odum EP (1969) The strategy of ecosystem development. Science 164:262-270

Odum EP (1985) Trends expected in stressed ecosystems. BioScience 35:419-422

Paine RT (1974) Intertidal community structure: experimental studies on the relationship between a dominant competitor and its principal predator. Oecologia 15:93-120

Petchey OL, Downing AL, Mittelbach GG, Persson L, Steiner CF, Warren PH, Woodward G (2004) Species loss and the structure and functioning of multitrophic aquatic ecosystems. Oikos 104:467-478

Pimm SL (1981) Food webs. Chapman \& Hall, London

Raffaelli DG (2000a) Trends in marine food research. J Exp Mar Biol Ecol 250:223-232

Raffaelli DG (2000b) Interactions between macro-algal mats and invertebrates in the Ythan estuary, Aberdeenshire, Scotland. Helgol Meersunters 54:71-79

Raffaelli D, Hawkins SJ (1996) Intertidal ecology. Chapman \& Hall, London

Raffaelli DG, Moller H (2000) Manipulative experiments in animal ecology-Do they promise more than they can deliver? Adv Ecol Res 30:299-330

Editorial responsibility: Martin Solan (Guest Editor), Newburgh, UK
Raffaelli DG, Raven J, Poole L (1998) Ecological impact of green macroalgal blooms. Annu Rev Mar Biol Oceanogr 36:97-125

Raffaelli DG, Balls P, Way S, Patterson IJ, Hohman SA, Corp N (1999) Major changes in the ecology of the Ythan estuary, Aberdeenshire: How important are physical factors? Aquat Conserv Mar Freshw Ecosyst 9: $219-236$

Raffaelli DG, van der Heijden M, van der Putten W, Kennedy E and 6 others (2002) Multi-trophic processes and ecosystem function. In: Loreau M, Naeem S, Inchausti P (eds) Biodiversity and ecosystem functioning. Oxford University Press, Oxford, p 147-154

Raffaelli D, Emmerson M, Solan M, Biles C, Paterson D (2003) Biodiversity and ecosystem processes in shallow coastal waters: an experimental approach. J Sea Res 49:133-141

Raffaelli D, Solan M, Webb TJ (2005) Do marine and terrestrial ecologists do it differently? Mar Ecol Prog Ser 304:283-289

Roberts CM, Hawkins JP (1999) Extinction risk in the sea. Trends Ecol Evol 14:241-246

Scherer-Lorenzen M, Potvin C, Koricheva J, Bornik Z, Hector A, Reynolds G, Schmid B (2004) The design of experimental tree plantations for functional biodiversity research. In: Scherer-Lorenzen M, Körner C, Schulze ED (eds) The functional significance of forest diversity. Springer-Verlag, Berlin, p 347-376

Schilthuizen M (2003) Forest ecologists go mega. Science 300: 1872

Solan M, Germano JD, Raffaelli DG, Warwick RM (2003) Benthic dynamics: in-situ surveillance of the sediment-water interface. J Exp Mar Biol Ecol 285(6):1-511

Solan M, Cardinale BJ, Downing AL, Engelhardt KAM, Ruesink JL, Srivastava DS (2004) Extinction and ecosystem function in the marine benthos. Science 306: $1177-1180$

Taylor R, Raven JA (2003) Survival strategies of Enteromorpha from eutrophic sites. In: Raffaelli DG, Solan M, Paterson D (eds) The estuaries of north-east Scotland. Coast Zone Top 5:31-40

Thrush SF, Whitalch RB, Pridmore RD, Hewitt JE, Cummings VJ, Wilkinson MR (1996) Scale-dependent recolonisation: the role of sediment stability in a dynamic sandflat habitat. Ecology 77:2472-2487

Thrush SF, Schneider DC, Legendre P, Whitalch RB, Dayton PK, Hewitt JE (1997) Scaling up from experiments to complete ecological systems: Where to next? J Exp Mar Biol Ecol 216:243-254

Tilman D (1997) Biodiversity and ecosystem properties. Science 278:1866-1867

Ulanowicz RE (1986) Growth and development: ecosystem phenomenology. Springer-Verlag, New York

Wilsey BJ, Potvin C (2000) Biodiversity and ecosystem functioning: importance of species evenness in an old field. Ecology 81:887-892

Yodzis P (1988) The indeterminacy of ecological interactions, as perceived through perturbation experiments. Ecology 69:508-515

Submitted: April 12, 2005; Accepted: October 21, 2005

Proofs received from author(s): March 7, 2006 